\title{
CORRECTION
}

\section{Correction to: Single-Inhaler Triple Therapy and Health-Related Quality of Life in COPD: The IMPACT Study}

\author{
Maggie Tabberer - C. Elaine Jones · Sally Kilbride - David M. G. Halpin • \\ David A. Lomas - Steven Pascoe $\cdot$ Dave Singh $\cdot$ Robert A. Wise · \\ Gerard J. Criner · Peter Lange $\cdot$ Mark T. Dransfield · MeiLan K. Han • \\ Fernando J. Martinez · Morrys C. Kaisermann · David A. Lipson
}

Published online: January 21, 2022

(C) Springer Healthcare Ltd., part of Springer Nature 2022

Correction to: Adv Ther (2020) 37:3775-3790

https://doi.org/10.1007/s12325-020-01409-8

In the original article the disclosures for the author MeiLan K. Han are missing. MeiLan K.

The original article can be found online at https://doi. org/10.1007/s12325-020-01409-8.

M. Tabberer $(\bowtie) \cdot$ S. Kilbride

GlaxoSmithKline plc, Stockley Park West, Uxbridge,

Middlesex, UK

e-mail: margaret.x.tabberer@gsk.com

C. E. Jones

GlaxoSmithKline plc, Research Triangle Park, NC, USA

D. M. G. Halpin

University of Exeter Medical School, College of

Medicine and Health, University of Exeter, Exeter, UK

D. A. Lomas

UCL Respiratory, University College London,

London, UK

S. Pascoe - M. C. Kaisermann - D. A. Lipson

GlaxoSmithKline plc, Collegeville, PA, USA

D. Singh

The Centre for Respiratory Medicine and Allergy,

Institute of Inflammation and Repair, Manchester

Academic Health Science Centre, University of

Manchester, Manchester University NHS

Foundation Trust, Manchester, UK
Han's disclosures should read as "MeiLan K. Han has received personal fees from GlaxoSmithKline, AstraZeneca, Boehringer Ingelheim, Merck and Mylan. Research support was also received from Novartis and Sunovion".

\section{R. A. Wise}

The Division of Pulmonary and Critical Care Medicine, Johns Hopkins University School of Medicine, Baltimore, MD, USA

\section{G. J. Criner}

Lewis Katz School of Medicine at Temple University, Philadelphia, PA, USA

P. Lange

University of Copenhagen, Copenhagen, Denmark

M. T. Dransfield

The Division of Pulmonary, Allergy, and Critical Care Medicine, Lung Health Center, University of Alabama at Birmingham, Birmingham, AL, USA

M. K. Han

University of Michigan, Pulmonary and Critical Care, Ann Arbor, MI, USA

\section{F. J. Martinez}

New York-Presbyterian Hospital/Weill Cornell Medical Center, New York, NY, USA

D. A. Lipson

Perelman School of Medicine, University of Pennsylvania, Philadelphia, PA, USA 